\title{
Abstracts from the 1997 Eastern Student Research Forum
}

\author{
Miami, Florida, USA* \\ * Held at the University of Miami (Miami, Florida, USA) on February 22, 1997.
SOLUBLE MEDIATORS FROM PRIMARY MOUSE THYMIC STROMAL CELL CULTURES PROTECT THE T CELL HYBRIDOMA 2B4.11.13 FROM TCR-MEDIATED ACTIVATION- INDUCED CELL DEATH

\section{B.O. Porter $\underline{\text { a }}$ and T.R. Malek}

${ }^{\text {a }}$ Department of Microbiology and Immunology, University of Miami School of Medicine, Miami, FL 33136 USA

Thymic stromal cells (TSC) influence intrathymic T cell development via both cell to cell interactions with thymocytes and the production of soluble factors (cytokines). Our goal was to characterize soluble activities produced by TSC which might regulate the growth, differentiation, and/or apoptosis of developing T cells. Primary mouse TSC lines were prepared from either one-day old BALB/c or C57BL/6 neonates by treating minced thymi with 2-deoxyguanosine, a nucleotide analog which selectively kills bone marrow-derived cells while leaving supporting stromal cells intact. As a model of apoptosis, the 2B4.11.13 $\mathrm{T}$ cell hybridoma was used, which exhibits marked activation-induced cell death (AICD) when cross-linked in vitro with soluble $2 \mathrm{C} 11$ anti-T cell receptor (TCR) monoclonal antibody (35-45\% cell viability with $2 \mathrm{C} 11$, as compared to 80 $90 \%$ in media controls; $p<0.001)$. Co-culture of either TSC or their filtered supernatants with 2B4.11.13 cells conferred dose-dependent protection against AICD, restoring 2B4.11.13 cell viability to $65-75 \%$ ( $p<$ 0.001 ), as measured by trypan blue exclusion and propidium iodide flow cytometry. Protection by TSC supernatant also extended to concanavalin A/IL-2-activated peripheral T cells, upon restimulation with concavalin A. After testing nearly thirty additional T, B, macrophage, fibroblast, and stromal cell line supernatants, only one bone marrow (S9) and 4 of 7 TSC lines exhibited this protective activity which was heat-resistant $\left(65^{\circ} \mathrm{C}\right.$ for $\left.1 \mathrm{hr}\right)$ and dialyzable, suggesting it is due to a stable molecule of less than $6000 \mathrm{MW}$. The eicosanoid prostaglandin $\mathrm{E}_{2}\left(\mathrm{PGE}_{2}\right)$ also conferred protection against $\mathrm{AICD}$ when used in the same 2B4.11.13 cell culture system at physiological concentrations. Additionally, treatment of TSC with indomethacin, a potent inhibitor of $\mathrm{PGE}_{2}$ synthesis, abrogated their protective effect. Thus, these data raise the possibilty that TSC may regulate intrathymic T cell development by protecting cells from TCR-mediated apoptosis via the secretion of $\mathrm{PGE}_{2}$ or a $\mathrm{PGE}_{2}$-like molecule.

\section{BIOGRAPHY}

Brian O. Porter was awarded the Best Overall University of Miami Presentation and the European Student Research Forum Travel Award for his presentation at the 1997 Eastern Student Research Forum. 


\title{
DEFECTIVE DEVELOPMENT OF PRE-B CELLS AND THE IMMUNODEFICIENCY IN AGING
}

\section{E.M. Sherwood ${ }^{\mathrm{a}}$ and R.L. Riley}

${ }^{a}$ Department of Microbiology and Immunology, University of Miami School of Medicine, Miami, FL 33136 USA

Aging is associated with decreased numbers of pre-B cells within the bone marrow of BALB/c mice. By 2 years of age, small pre-B cells (CD43- CD25+ B220+ cu+) are reduced by $\sim 80 \%$. Detailed characterization of B lineage precursor cells indicates that the representation of pro-B cells $(C D 43+C D 25-B 220+c u+)$ and, importantly, early pre-B cells (CD43+CD25+ B220+ cu+) is unchanged with senescence. Therefore, the capacity to productively rearrange and express $\mu$ heavy chain is maintained in old age. However, large pre-B cells (CD43- CD25+ B220+ cu+) are also reduced by $\sim 80 \%$ in 2 year old mice. Unlike pre-B cells (CD43+ $\mathrm{CD} 25+\mathrm{B} 220+\mathrm{ctu}+$ ) and lat e stage pre-B cells (small CD43- CD25+), which have low mitotic activity in vivo $(\sim 5-10 \%$ of cells in $\mathrm{S}+\mathrm{G} 2 / \mathrm{M})$, large CD43- CD25+ pre-B cells are highly mitotically active $(\sim 50-80 \%$ of cells in $S+G 2 / M)$. In aged mice, the numbers of proliferating pre-B cells are dramatically reduced. This occurs coincident with the reduction in the incidence of pre-B cells which proliferate in response to IL-7 in vitro (IL-7 CFU). Notably, mobilization into the proliferative pre-B cell pool requires both a supportive microenvironment and active selection via the $\mathrm{u} / \mathrm{VpreB} /($ lambda $) 5$ pre- $\mathrm{B}$ cell receptor. Therefore, the decline in small pre-B cells in old age may result from deficient selection of early pre-B cells (CD43+ CD25+) into the mitotically active large pre-B cell compartment.

\section{BIOGRAPHY}

Erin M. Sherwood was awarded the First Place Poster Presentation in the Graduate Division for her presentation at the 1997 Eastern Student Research Forum.

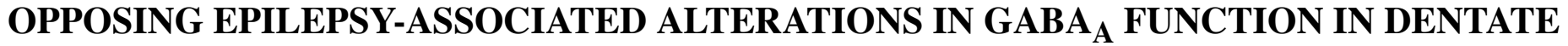 GYRUS AND CA1 NEURONS}

\author{
J.W. Gibbs III ${ }^{\mathrm{a}}$, M.D. Shumate, and D.A. Coulter
}

${ }^{\text {a }}$ Medical School of Virginia, Richmond, VA 23298, USA

The enhanced limbic excitability underlying development of temporal lobe epilepsy (TLE) involves multiple alterations within the limbic system. One alteration contributing to excitability differences is the loss of GABAergic inhibition. In the present study, we assess potential alterations of postsynaptic GABAergic function associated with TLE. TLE was elicited using pilocarpine (PILO). Rats were injected with scopolamine $1 \mathrm{mg} / \mathrm{kg}$, followed by PILO $350 \mathrm{mg} / \mathrm{kg}$. PILO-induced status epilepticus was terminated following 1-5 hrs with diazepam $4 \mathrm{mg} / \mathrm{kg}$. After 2-4 weeks, animals were monitored to confirm spontaneous seizures (mean 1.2 seizures/day). PILO and subconvulsive PILO $(35 \mathrm{mg} / \mathrm{kg}$ ) control animals were decapitated, and slices prepared. Hippocampal dentate granule (DG) and CA1 neurons were accurately dissociated, and recorded using whole-cell patch clamp techniques. The functional density of $\mathrm{GABA}_{\mathrm{A}}$ receptors, assessed by applying $\mathrm{GABA}(1 \mathrm{mM})$ and normalizing the response to cellular capacitance, increased in PILO DG neuron animals by $75 \%$. Increased GABA $A_{A}$ density in DG was not accompanied by GABA potency alterations. However, the sensitivity of DG GABA $A_{A}$ responses to block by zinc increased by $167 \%$. In contrast, functional density of $\mathrm{GABA}_{\mathrm{A}}$ receptors in CA1 decreased by $52 \%$ in PILO animals relative to controls, accompanied by an increase in potency of $\mathrm{GABA}\left(\mathrm{EC}_{50}\right.$ of GABA decreased from 45.7 to 
25.3 uM in controls and PILOs, respectively). All PILO animals exhibited significant sprouting of mossy fibers in the DG (mean Timm's score of 2.1) and controls exhibited little or no sprouting (mean score 0.1). GABA receptor properties were significantly altered by development of an epileptic condition in both DG and CA1 neurons. DG neurons have enhanced density of GABA receptors following development of TLE, while $\mathrm{CA} 1$ neurons have reduced density of $\mathrm{GABA}_{\mathrm{A}}$ receptors. However, the enhanced zinc sensitivity of epileptic DG GABA receptors could result in a dynamic disinhibition resulting from blockade of inhibition by released zinc, particularly considering the enhanced sprouting evident in this TLE model. [Supported by NIH Grants NS-32403, PO1 NS-25630, and MD/PhD program of MCV.]

\title{
BIOGRAPHY
}

John W. Gibbs III was awarded the Second Place Oral Presentation in the Graduate Division for his presentation at the 1997 Eastern Student Research Forum.

\section{THE ROLE OF THE CYTOPLASMIC DOMAIN OF THE COMMON GAMMA SUBUNIT OF THE IL-2 RECEPTOR IN LIGAND INTERNALIZATION}

\author{
$\underline{\text { A.J. Fadell }}{ }^{\mathrm{a}}$, J.A. Hamilton, and T.R. Malek
}

${ }^{\text {a }}$ University of Miami School of Medicine, Miami, FL 33101 USA

The common gamma chain ((gamma)c) functionally participates in several cytokine receptors, including IL2, IL-4, IL-7, IL-9, and IL-15. This sharing suggests that (gamma)c contributes structurally to a common functional role in cytokine:receptor interactions. An important step in defining the role of (gamma)c in cytokine:receptor interactions is to define which domains are involved in this process. The current study has focused on developing mutants to the cytoplasmic domain of (gamma)c to investigate which subregions might play a role in both ligand:receptor internalization and the regulation of cell surface levels of (gamma)c. Mutants were generated that contained several deletions in the cytoplasmic tail of mouse (gamma)c. These constructs have been transiently transfected into Cos 7 cells and examined by both FACS analysis and Western blotting for expression of the truncated proteins as compared to wild type full length $* \mathrm{c}$. These studies indicate that truncation of the cytoplasmic tail of (gamma)c results in enhanced cell surface levels. The next series of experiments will involve co-transfection of the (gamma)c mutants with both IL-2R (alpha) and (beta) chains into Cos-7 cells to examine their ability to internalize IL-2. It is predicted that a subdomain will be identified demonstrating the role of (gamma)c in cytokine receptor internalization.

\section{BIOGRAPHY}

Tony J. Fadell was awarded the Second Place Poster Presentation in the Medical Division for his presentation at the 1997 Eastern Student Research Forum.

\section{ACUTELY SODDED EPTFE GRAFTS PRODUCE ONLY PROSTACYCLIN: A QUALITATIVE DIFFERENCE TO SAPHENOUS VEINS}

\section{$\underline{\text { SB Desai }}{ }^{\mathrm{a}}$, DG Cable, MR Phillips, HV Schaff}

${ }^{a}$ Mayo Clinic, 13740 Pennock Ave., Apple Valley, MN, USA

A selective subset of patients require prosthetic graft material for revascularization. Though arterial prosthetic grafts of large caliber perform acceptably, grafts of $<6 \mathrm{~mm}$ exhibit a high attrition rate. Microvessel 
endothelial sodding of these grafts is proposed to provide a functional endothelial layer, thereby improving patency. However, aggressive antiplatelet therapy is required following implantation and, upon cessation of an antiplatelet regimen, graft patency declines. The present investigation was designed to address the acute production of vasoactive substances in microvessel endothelial sodded ePTFE grafts compared to a "goldstandard", the saphenous vein.

Equal lengths of canine saphenous veins and acutely sodded ePTFE grafts (canine falciform ligament endothelial source) were evaluated in a superfusion bioassay. Basal secretion of vasoactive substances from saphenous veins relaxed the biodetector ring $10.3 \pm 2.9 \%(\mathrm{n}=10)$. Relaxation with acetylcholine stimulation was $50.3 \pm 10.2 \%$ in veins, reduced to $10.0 \pm 6.4 \%$ with indomethacin and $24.4 \pm 13.9 \%$ with L-NMMA pretreatment ( $\mathrm{n}=10,8,6$, respectively; $p<0.05 \mathrm{t}$-test). Calcium ionophore stimulation produced biodetector relaxation of $100.2 \pm 22.6 \%(\mathrm{n}=9)$; indomethacin and L-NMMA significantly reduced biodetector relaxation to $38.1 \pm 15.1 \%$ and $57.4 \pm 14.8 \%$, respectively $(\mathrm{n}=8,7 ; p<0.05)$. Basal secretion of vasoactive substances from ePTFE grafts relaxed the biodetector ring $1.1 \pm 3.1 \%(n=11)$. Acetylcholine and calcium ionophore produced $49.2 \pm 7.0 \%$ and $36.9 \pm 9.0 \%$ relaxations, respectively $(n=10,6)$. Indomethacin reduced relaxations to $20.2 \pm 9.2 \%$ and $12.5 \pm 4.3 \%$ with acetylcholine and calcium ionophore stimulation, respectively $(n=10,9)$. LNMMA had no effect on ePTFE release of vasoactive substances. Scanning electron microscopy demonstrated endothelium presence in both veins and grafts.

Though acutely sodded ePTFE grafts produce vasoactive substances detectable by superfusion bioassay, this contribution is quantitatively and qualitatively different than the release from saphenous veins. The acutely sodded ePTFE produced only prostanoid while saphenous veins produced both nitric oxide and prostanoids. The differential function of the endothelium noted may explain, in part, the reduced patency of sodded ePTFE and the requirement for aggressive antiplatelet therapy.

\section{BIOGRAPHY}

Sudhein B. Desai was awarded the Outstanding Surgery Presentation for his presentation at the 1997 Eastern Student Research Forum.

\section{CONSTRUCT AND CELL TYPE DEPENDENT DIFFERENCES IN HIV-1 GENE REGULATION}

\section{J. Favaro $\_$and S.J. Arrigo}

${ }^{a}$ Department of Microbiology and Immunology, Medical University of South Carolina, Charleston, SC 29425 USA

Human immunodeficiency virus type 1 (HIV-1) Rev is a $19 \mathrm{kd}$ protein necessary for viral replication. Rev functions by binding to HIV-1 RNA at the Rev Response Element (RRE). Rev has several functions: inhibition of RNA splicing, enhancement of RNA export to the cytoplasm, stabilization of the RNA, and promotion of translation. The effect of the Rev protein on HIV-1 gene regulation was investigated in COS and T cells. Several HIV-1 constructs with varying levels of splicing complexity were transiently transfected into both cell types. An inhibitory effect of Rev on the level of splicing and a positive effect of Rev on the cytoplasmic accumulation of unspliced and partially spliced HIV-1 RNAs was seen in COS cells. An analysis of the RNA distribution in T cells revealed similar levels of splicing inhibition. However, the cytoplasmic accumulation of partially spliced RNA was not dependent on Rev. While certain phenotypic manifestation varied depending on cell type, the specific RNA, and construct type, all results are consistent with Rev initially leading to the inhibition of splicing of the RNA and subsequently to the enhanced nuclear export of that RNA. To more fully understand the nuclear export function of Rev, it is currently being attempted to 
further localize RRE-containing RNAs to the cytoplasm in the presence or absence of Rev.

\section{BIOGRAPHY}

Justin Favaro was awarded the Outstanding Microbiology and Immunology Presentation in the Graduate Division for his presentation at the 1997 Eastern Student Research Forum.

Copyright $(C) 1997$ by MJM 